\title{
Effects of Material Nonlinearity on the Global Analysis and Stability of Stainless Steel Frames
}

\author{
Fiona Walport ${ }^{a}$, Leroy Gardner ${ }^{a}$, Esther Real ${ }^{b}$, Itsaso Arrayago ${ }^{b}$, David Nethercot ${ }^{a}$ \\ Department of Civil Engineering, Imperial College London, UK ${ }^{(a)}$, \\ Department of Civil and Environmental Engineering, Universitat Politècnica de Catalunya, Barcalona, \\ $\operatorname{Spain}^{(b)}$
}

\begin{abstract}
In structural frames, second order effects refer to the internal forces and moments that arise as a result of deformations under load (i.e. geometrical nonlinearity). EN 1993-1-1 states that global second order effects may be neglected if the critical load factor of the frame $\alpha_{\mathrm{cr}}$ is greater than 10 for an elastic analysis, or greater than 15 when a plastic global analysis is used. No specific guidance is provided in EN 1993-1-4 for the design of stainless steel frames, for which the nonlinear stress-strain behaviour of the material will result in greater deformations as the material loses its stiffness. A study of the effects of material nonlinearity on the stability of stainless steel frames is presented herein. A series of different frame geometries and loading conditions are considered. Based on the findings, proposals for the treatment of the influence of material nonlinearity on the global analysis and design of stainless steel frames are presented.
\end{abstract}

\section{Keywords}

Continuous Strength Method, Frame stability, Global analysis, Numerical Modelling, Second order effects, Stainless steel

\section{Introduction}

Stainless steel is widely used across a range of industries with its key advantage over ordinary carbon steel being its corrosion resistance and durability. Although a number of design standards for stainless steel currently exist, their provisions have generally been based on a presumed equivalence with the carbon steel design rules. However, stainless steel and carbon steel have distinctly different material characteristics; while carbon steel is accurately characterised by a bilinear (elastic, perfectly plastic) stress-strain response, stainless steel exhibits nonlinear rounded stress-strain behaviour with no sharply defined yield point. It is important that the codes reflect these differences so as to ensure safe, efficient, and structurally sound design. The current European rules for global analysis and design are examined in this paper, assessing whether the methods provided are suitable for stainless steel. Particular attention is given to the extent to which the differences between the behaviour of stainless steel and carbon steel frames are adequately recognised.

EN 1993-1-4 ${ }^{[1]}$ gives supplementary guidance for the design of stainless steel structures that complement the design rules given for structural carbon steel in EN 1993-1-1 ${ }^{[2]}$. Section 5 of EN 1993-1-1 outlines the rules for structural analysis with detailed subsections on structural modelling, global analysis and imperfections, as well as methods of analysis considering material nonlinearities. The guidance on material nonlinearities largely relates to the occurrence of traditional idealised plastic hinges, as seen in carbon steel structures. However, such hinges do not form in stainless steel structures; instead zones of plasticity with gradually reducing stiffness, but with peak capacities well in excess of the traditional plastic moment are exhibited ${ }^{[3]}$. EN 1993-1-1 also states that "elastic global analysis may be used in all cases" and that "elastic global analysis should be based on the assumption that the stress-strain behaviour of the material is linear, whatever the stress level is". The supplementary rules for stainless steel give no additional information for the global analysis of stainless steel structures, though an analytical expression for the description of the rounded stress-strain response of stainless steel based on the two stage Ramberg-Osgood model ${ }^{[4,5,6]}$ is given in Annex $\mathrm{C}^{[1]}$. This paper assesses whether the assumption of an elastic global analysis is sufficient or whether, due to the significant nonlinearity of stainless steel, a plastic global analysis is necessary.

Fig. 1 shows typical load-displacement paths determined from different types of structural analyses, displaying the effects of material and geometric nonlinearities and their importance in the global analysis of structures. Geometrical nonlinearities may result either from global imperfections and deformations associated with frame instability, known as ' $P-\Delta$ ' effects, or member imperfections and deformations associated with member instability, known as ' $P-\delta$ ' effects. Whether or not global second order effects can be ignored depends on the extent to which they modify the structural behaviour or increase the forces and moments in the members. In common with other structural steel design standards, this assessment is made in EN 1993-1-1 ${ }^{[2]}$ on the basis of the value of the critical load factor $\alpha_{\mathrm{cr}}$, which is the amount by which the design loading would have to be increased to cause elastic instability of the frame in a global sway mode. Second order effects are deemed to be sufficiently small to be ignored when $\alpha_{\mathrm{cr}}>10$ for an elastic analysis and $\alpha_{\mathrm{cr}}>$ 15 for a plastic analysis. These guidelines were developed on the basis of linear elastic or linear elastic, perfectly plastic material behaviour; their validity in the case of the nonlinear rounded material response of stainless steel is assessed in this paper. 


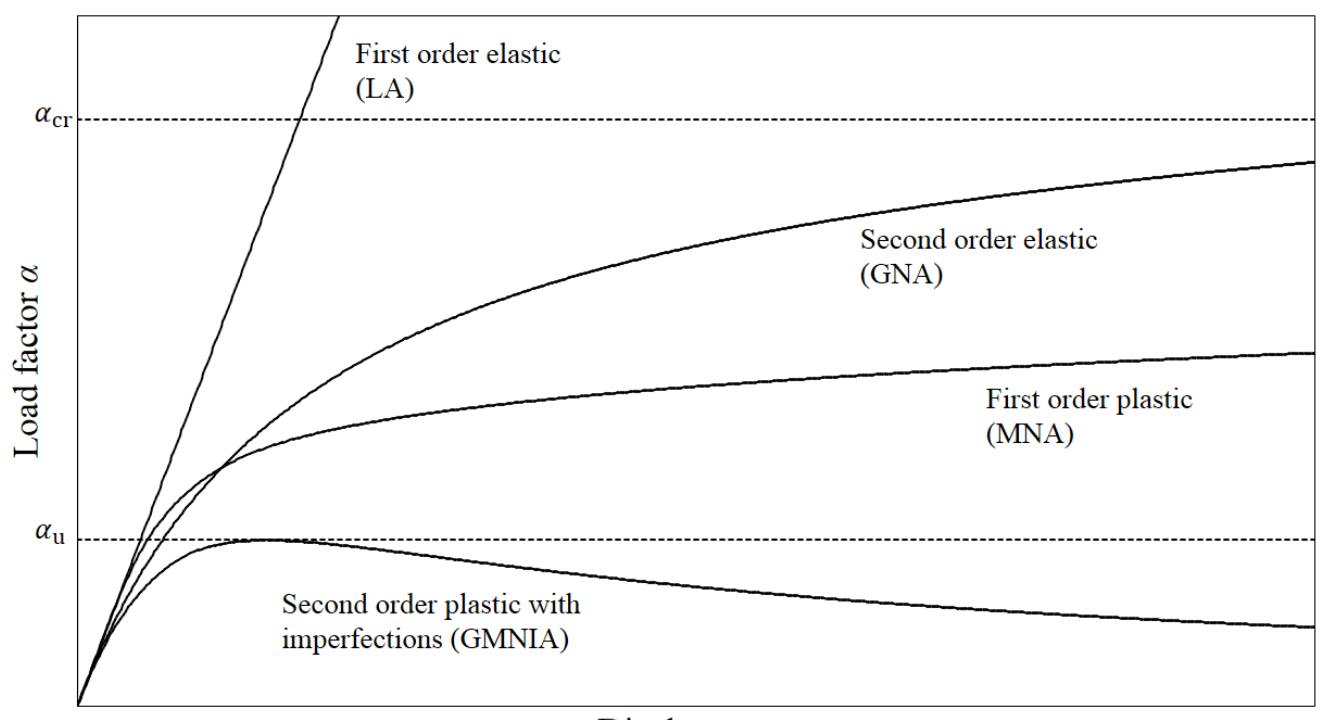

Displacement

Fig. 1 Methods of structural analysis (LA = Linear Analysis; GNA = Geometrically Nonlinear Analysis; MNA = Materially Nonlinear Analysis; GMNIA = Geometrically and Materially Nonlinear Analysis with Imperfections)

The assessment is carried out by first generating benchmark results for a series of frames using geometrically and materially nonlinear analyses with imperfections (GMNIA). The Continuous Strength Method (CSM) is used to mimic local buckling in the beam element models. The influence of material nonlinearity is observed and a proposal to account for the effect of plasticity on the generation of second order effects is made. In Section 3 the current design rules for stainless steel are applied to the benchmark frames, considering different global analysis options as well as cross-section and member checks. Based on the results from the study, the consequences of material nonlinearity and stiffness degradation on the deterioration of frame stability are discussed in Section 4, concluding with design recommendations.

\section{Benchmark Frame Modelling}

\subsection{Introduction}

Finite element (FE) models were developed using the general purpose FE software ABAQUS ${ }^{[7]}$. Portal frames constructed using welded I-sections were simulated with the geometry of the standard European HEB 340 cross-section. This section is a Class 1 cross-section in bending and is therefore deemed capable of reaching and maintaining its full plastic moment resistance, according to the traditional definition. The 2-noded linear Timoshenko B31OS beam element, from the ABAQUS element library, was employed to create the models and was used in all numerical simulations. Fig. 2 shows the basic frame configuration modelled in this study. Both pinned and fixed boundary conditions were considered at the column bases as well as a number of loading arrangements, as summarised in Table 1 . The width $L$ of all frames was taken to be $10 \mathrm{~m}$, with the frame heights $h$ varying between $5 \mathrm{~m}$ and $15 \mathrm{~m}$ for each case.

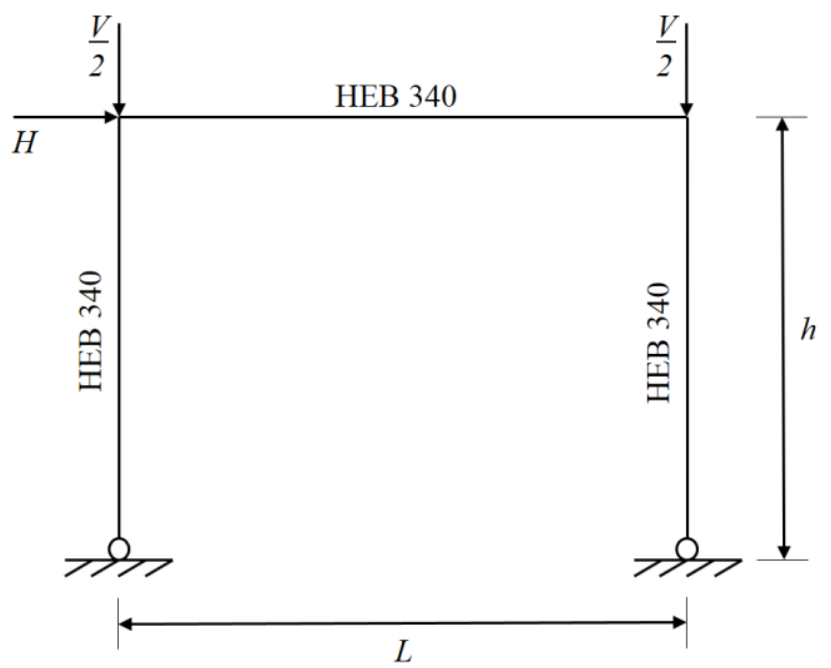

Fig. 2 Details of portal frames modelled 


\begin{tabular}{lll}
\hline Frame case no. & Boundary conditions & Horizontal loading $\boldsymbol{H}$ \\
\hline 1 & Fixed & $0.05 \mathrm{~V}$ \\
2 & Fixed & $0.2 \mathrm{~V}$ \\
3 & Fixed & $0.5 \mathrm{~V}$ \\
4 & Pinned & 0
\end{tabular}

The members were connected via fixed multi-point constraint ties at their ends providing full continuity. The frames were constrained out-of-plane such that only in-plane major axis buckling was considered. 100 elements were used to model each of the members, to accurately capture the spread of plasticity, and the modified Riks method ${ }^{[7]}$ was used to trace the full load-deformation response of the frames. The displacements, load factors, section forces and section moments were extracted from all analyses.

In the following subsections, the elastic buckling load factors $\alpha_{\text {cr }}$ from a linear buckling analysis (LBA) and ultimate load factors $\alpha_{\mathrm{u}}$ from a geometrically and materially nonlinear analysis with imperfections (GMNIA) of the considered frames are determined. A comparison of the level of moment amplification in the frames in the case of elastic and plastic analysis is then carried out, and a proposal to account for the influence of plasticity on frame stability is made.

\subsection{Elastic buckling load factor $\alpha_{\text {cr }}$}

There are two common methods for determining the elastic critical load factor $\alpha_{\text {cr }}$ of frames. The first method is the approximate method, originally proposed in [8], and given in Clause 5.2.1(4) of EN 1993-1-1; this approach can be used for "portal frames with shallow roof slopes and beam-and-column type plane frames when the axial compression in the beams is not significant". The second method is to conduct a linear buckling analysis of the frame under the applied loading conditions and to take $\alpha_{\mathrm{cr}}$ as the Eigenvalue corresponding to the lowest sway buckling mode. This represents the factor by which the applied loading would need to be increased to cause elastic instability of the frame in a global sway mode. Throughout this study, $\alpha_{\text {cr }}$ has been determined using the more accurate Eigenvalue approach, under the applied loading that causes collapse of the frame (i.e. $\alpha_{\mathrm{u}}=1.0$ - see Section 2.3), as predicted by GMNIA.

\subsection{Ultimate load factor $\alpha_{\mathrm{u}}$}

The calculation of the ultimate load factors of the frames from geometrically and materially nonlinear analyses with imperfections (GMNIA) is described in this section. These are taken as the 'true' failure load factors of the frames and are used in this study as benchmark load factors, against which the various design approaches considered in Section 3 are assessed.

\subsubsection{Material modelling}

For the benchmark GMNIA models, the rounded nonlinear stress-strain response of stainless steel, defined on the basis of the two-stage Ramberg-Osgood formulation ${ }^{[4]}$, given by Eqs. (1)-(2), where $\varepsilon$ and $\sigma$ are the strain and stress respectively, $f_{\mathrm{y}}$ is the yield $\left(0.2 \%\right.$ proof) stress, $E$ is the Young's modulus, $f_{\mathrm{u}}$ is the ultimate stress, $E_{\mathrm{y}}$ is the tangent modulus at the yield $\left(0.2 \%\right.$ proof) stress, defined by Eq. (3), $\varepsilon_{\mathbf{u}}$ is the ultimate strain, and $n$ and $m$ are the strain hardening exponents, was employed.

$$
\begin{gathered}
\varepsilon=\frac{\sigma}{E}+0.002\left(\frac{\sigma}{f_{\mathrm{y}}}\right)^{n} \quad \text { for } \quad \sigma \leq f_{\mathrm{y}} \\
\varepsilon=0.002+\frac{f_{\mathrm{y}}}{E}+\frac{\sigma-f_{\mathrm{y}}}{E_{\mathrm{y}}}+\varepsilon_{\mathrm{u}}\left(\frac{\sigma-f_{\mathrm{y}}}{f_{\mathrm{u}}-f_{\mathrm{y}}}\right)^{m} \quad \text { for } \quad f_{\mathrm{y}}<\sigma \leq f_{\mathrm{u}} \\
E_{\mathrm{y}}=\frac{E}{1+0.002 n \frac{E}{f_{\mathrm{y}}}}
\end{gathered}
$$

For this study, a single stress-strain curve for a typical austenitic stainless steel has been considered, with $E=200000 \mathrm{~N} / \mathrm{mm}^{2}, f_{\mathrm{y}}=310 \mathrm{~N} / \mathrm{mm}^{2}, f_{\mathrm{u}}=670 \mathrm{~N} / \mathrm{mm}^{2}, n=6.3$, and $\varepsilon_{\mathrm{u}}$ and $m$ defined by Eqs. (4) and (5), respectively ${ }^{[1]}$. This stress-strain curve is depicted, up to $5 \%$ strain, in Fig. 3.

$$
\begin{gathered}
\varepsilon_{\mathrm{u}}=1-\frac{f_{\mathrm{y}}}{f_{\mathrm{u}}} \\
m=1+3.5 \frac{f_{\mathrm{y}}}{f_{\mathrm{u}}}
\end{gathered}
$$




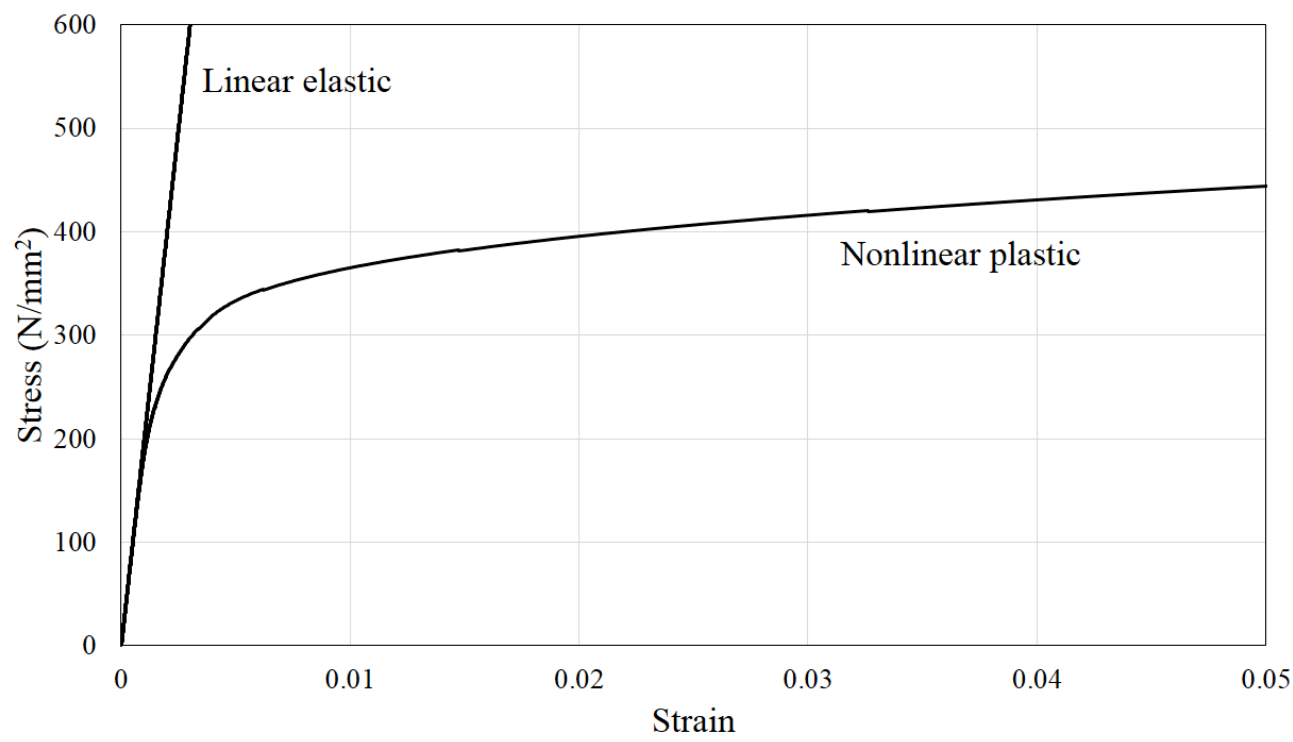

Fig. 3 Stress-strain response for a typical austenitic stainless steel defined through the two-stage Ramberg-Osgood model

\subsubsection{Imperfections and residual stresses}

Initial imperfections can have a significant effect on the development and spread of plasticity, and hence the stability of structural members and frames ${ }^{[9]}$. In this study, an initial member out-of-straightness in the form of a half-sine wave and with a magnitude of $1 / 1000$ of the member length was assumed while, for the initial frame imperfection an out-ofplumbness $1 / 200$ of the frame height was assumed, as recommended in EN 1993-1-1 ${ }^{[2]}$. The geometric imperfections were incorporated into the models in the most unfavourable directions considering the applied loading and boundary conditions. The initial frame out-of-plumbness was applied as an equivalent horizontal force.

Residual stresses can influence the performance of structural members by causing premature yielding and loss of stiffness, resulting in reduced ultimate load carrying capacity. Residual stress distributions in stainless steel sections differ from those in equivalent carbon steel sections due to differences in physical and thermal properties ${ }^{[10]}$. The modified ECCS residual stress model ${ }^{[11]}$ developed for stainless steel welded I-sections by Yuan et al. ${ }^{[12]}$ has been incorporated into the FE models. Forty-one integration points were used within each flange and web of the sections to ensure that the residual stress distribution and subsequent spread of plasticity under the applied loading could be accurately captured. The residual stresses were introduced by defining the initial stress values at the 121 integration points across the open section, through the SIGINI user subroutine ${ }^{[7]}$.

\subsubsection{Simulation of local buckling}

Advanced structural analysis is commonly carried out using finite element models constructed with beam elements. Beam elements are incapable of capturing the effects of local buckling as they are nondeforming line elements. However, disregarding local buckling can lead to overestimations of system strengths leading to unsafe design. This is a concern for all materials but particularly for stainless steel due to the nonlinear stress-strain response and the pronounced development of strain hardening. Fig. 4 shows the results from an example simply-supported beam under 3-point bending. While the beam FE model never reaches a peak moment, an equivalent shell FE model (with local imperfections of amplitude 1/200 of the plate width) which allows for local buckling, exhibits a peak moment of about 1.35 times the plastic moment capacity $M_{\mathrm{pl}}$, with $M_{\mathrm{pl}}$ is the capacity predicted for the modelled Class $1 \mathrm{HEB} 340$ cross-section according to EN 1993-1-4. 


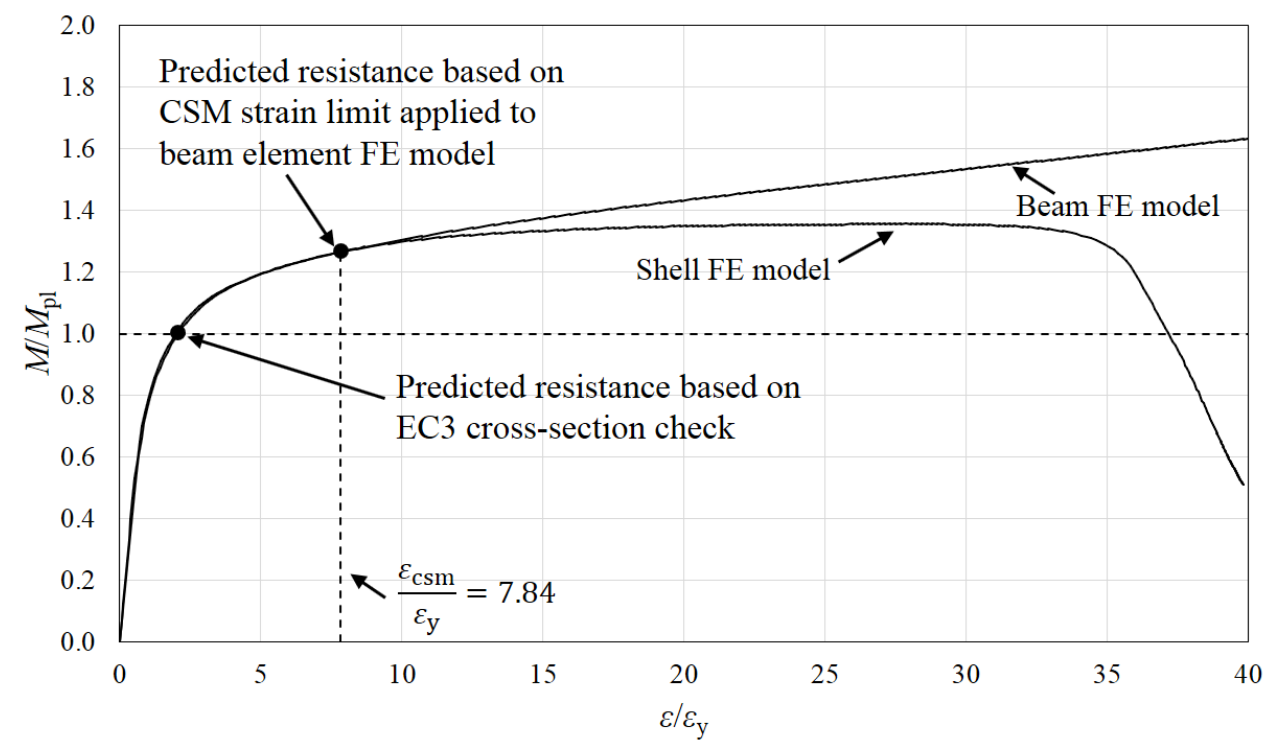

Fig. 4 Response from an HEB 340 simply-supported beam under 3-point bending

To simulate local buckling in the beam element models, and also to allow for the beneficial influence of strain hardening, the strain limits defined by the Continuous Strength Method (CSM) are employed herein. The CSM is a deformationbased method that replaces the concept of cross-section classification with a nondimensional measure of the cross-section deformation capacity, allowing for the incorporation of strain hardening ${ }^{[13]}$. The CSM has two key components (i) a continuous 'base curve' to determine the maximum strain that a cross-section can withstand under the applied loading, and (ii) an elastic, linear hardening material model allowing for strain hardening, to enable design stresses greater than the $0.2 \%$ proof stress to be achieved ${ }^{[14]}$. In this part of the study, only the CSM maximum strain $\varepsilon_{\text {csm }}$ was employed, and the ultimate load factor of the frames $\alpha_{\mathrm{u}}$ was defined either at an instability induced natural peak in load-deformation response or at the point where the CSM strain limit is achieved at any cross-section.

The CSM base curve is given by Eq. (6), where $\bar{\lambda}_{\mathrm{p}}$ is the local cross-sectional slenderness, $\varepsilon_{\mathrm{y}}$ is the yield strain equal to $f_{\mathrm{y}} / E, \varepsilon_{\mathrm{u}}=1-f_{\mathrm{y}} / f_{\mathrm{u}}$ and $C_{1}=0.10$ for austenitic stainless steel.

$$
\frac{\varepsilon_{\mathrm{csm}}}{\varepsilon_{\mathrm{y}}}=\left\{\begin{array}{lll}
\frac{0.25}{\bar{\lambda}_{\mathrm{p}}^{3.6}} \leq \min \left(15, \frac{C_{1} \varepsilon_{\mathrm{u}}}{\varepsilon_{\mathrm{y}}}\right) & \text { for } & \bar{\lambda}_{\mathrm{p}} \leq 0.68 \\
\left(1-\frac{0.222}{\bar{\lambda}_{\mathrm{p}}^{1.05}}\right) \frac{1}{\bar{\lambda}_{\mathrm{p}}^{1.05}} & \text { for } & \bar{\lambda}_{\mathrm{p}}>0.68
\end{array}\right.
$$

The cross-sectional slenderness is calculated using Eq. (7), where $f_{\mathrm{y}}$ is the yield stress and $\sigma_{\mathrm{cr}}$ is the elastic critical buckling stress of the cross-section. The software CUFSM ${ }^{[15]}$ was used to calculate the elastic critical buckling stress of the cross-section under various in-plane stress distributions ranging from pure compression to pure bending. The CSM strain limit, as with cross-section classification, can be based on the instantaneous stress distribution within the section under consideration, with pure compression $\left(\psi=\sigma_{2} / \sigma_{1}=1\right)$ being the most severe and therefore leading to the lowest CSM strain limit; with increasing bending contributions, the stress distribution becomes more favourable (towards $\psi=$ -1 for pure bending) and hence the CSM strain limit increases. This is illustrated in Fig. 5 for an HEB 340 section with $f_{\mathrm{y}}=310 \mathrm{~N} / \mathrm{mm} 2$ under compression and major axis bending. The instantaneous strain limit $\varepsilon_{\mathrm{csm}}$, determined for the local slenderness $\bar{\lambda}_{\mathrm{p}}$ corresponding to the elastic buckling stress of the cross-section from CUFSM at each increment of the global structural analysis, is used throughout this study.

$$
\bar{\lambda}_{\mathrm{p}}=\sqrt{\frac{f_{\mathrm{y}}}{\sigma_{\mathrm{cr}}}}
$$




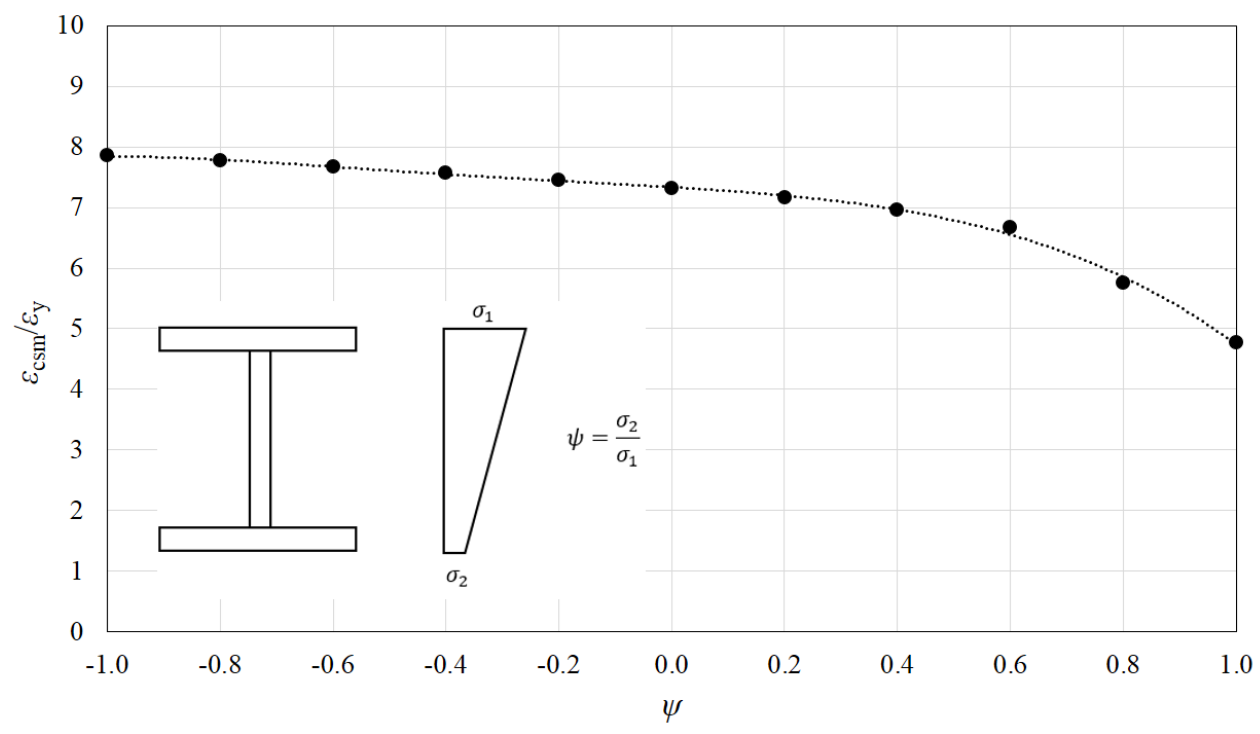

Fig. $5 \quad$ Normalised CSM strain limit for an HEB 340 section under varying stress distributions

The CSM strain limit is applied to strains output from the structural analysis, but averaged over a finite length of member. Using average strains over a finite length of member is preferable to using peak strain to avoid excessive sensitivity to the mesh size and the occurrence of spurious results, to reflect the fact that plastic hinges and local buckling require a finite length over which to develop, and to allow for local moment gradient effects. Based on ongoing work at Imperial College, it has been shown that the strains from the structural analysis should be averaged over a characteristic length, related to the local buckling half wavelength. Lay ${ }^{[16]}$ proposed Eq. (8) for estimating the local buckling half wavelength $L_{\text {buckle }}$ of I-sections in the inelastic regime, where $b$ is the overall flange width, $t_{\mathrm{f}}$ is the flange thickness, $t_{\mathrm{w}}$ is the web thickness, $A_{\mathrm{f}}$ is the flange area and $A_{\mathrm{w}}$ is the web area. Strains are averaged over the length $L_{\text {buckle }}$ along the member in this study, and this length defines the maximum element size to be used in the FE models.

$$
L_{\text {buckle }}=1.42 b \frac{t_{\mathrm{f}}}{t_{\mathrm{w}}}\left(\frac{A_{\mathrm{w}}}{A_{\mathrm{f}}}\right)^{0.25}
$$

For the HEB 340 cross-section considered in Fig. 4, the cross-section slenderness under bending $\bar{\lambda}_{\mathrm{p}}$ is equal to 0.38 , which corresponds to a normalised CSM strain limit $\varepsilon_{\mathrm{csm}} / \varepsilon_{\mathrm{y}}=7.84$. Applying this strain limit to the beam FE model see Fig. 4 - results in a capacity prediction close to but on the safe side of the peak moment from the shell FE model, and considerably above the plastic moment capacity, which represents the EN 1993-1-4 cross-section resistance prediction for this Class 1 section.

In all further analyses in this study, ultimate load factors as predicted by GMNIA with the CSM strain limit, $\alpha_{\mathrm{u}}$, are taken to be the 'true' benchmark failure values of the considered frames. In cases where the peak load occurs before the CSM strain limit is reached, the peak load is simply taken as the ultimate load. This is illustrated in Fig. 6 for the frames considered in this study.

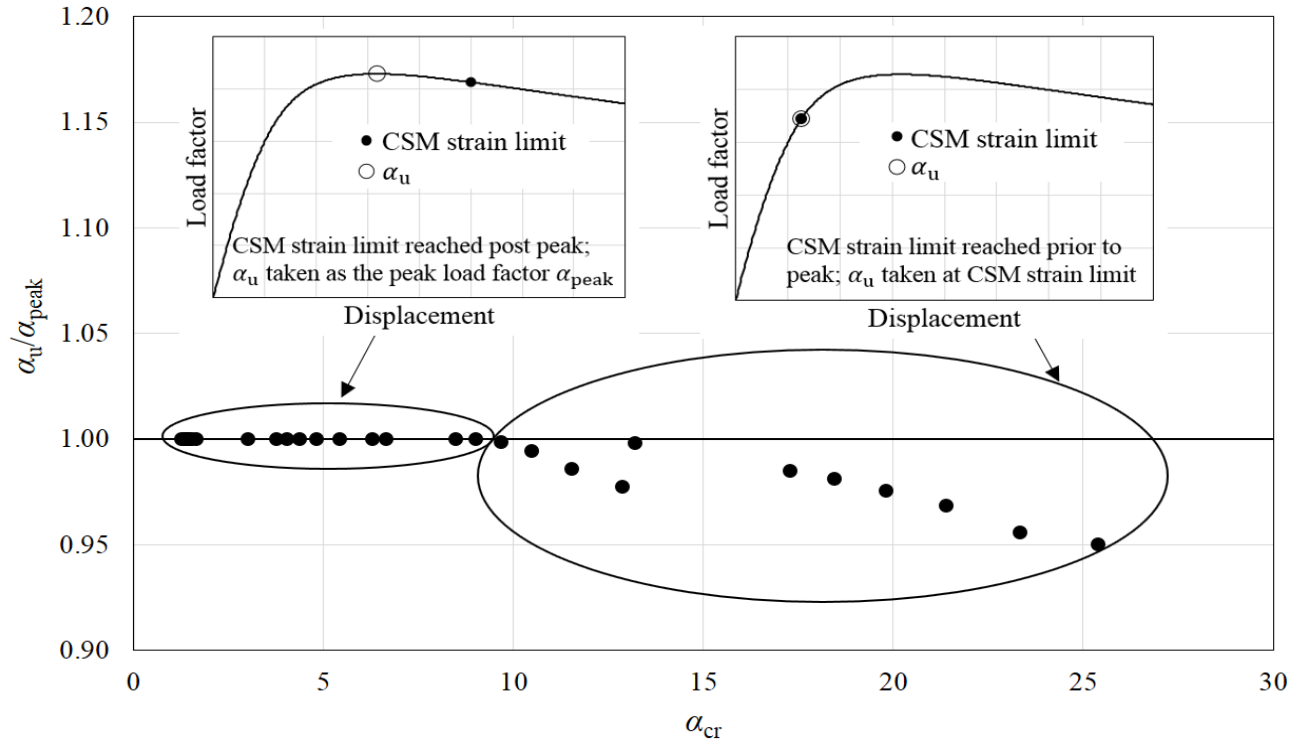

Fig. 6 Comparison of the ultimate load factors $\alpha_{\mathrm{u}}$, considering the CSM strain limit to simulate local buckling, and the peak load factors $\alpha_{\text {peak }}$ 


\subsection{Results}

The nonlinear stress-strain behaviour of stainless steel results in greater deformations as the material loses its stiffness. To assess the consequences of this material nonlinearity on frame stability, a comparison between first and second order moments has been made assuming both elastic and nonlinear plastic material behaviour. In the elastic regime, Merchant ${ }^{[17]}$ proposed an amplification factor $k_{\mathrm{amp}}$, which is included in EN 1993-1-1 ${ }^{[2]}$ and given by Eq. (9), to be used to estimate second order sway moments from a first order analysis.

$$
k_{\mathrm{amp}}=\frac{1}{1-\frac{1}{\alpha_{\mathrm{cr}}}}
$$

where $\alpha_{\mathrm{cr}}$ is the factor by which the applied loading must be increased to cause elastic instability of the frame in a global sway mode.

The ratios of the maximum moments extracted from the FE frame models at $\alpha_{\mathrm{u}}$ using a second order elastic analysis $M_{\mathrm{GNA}}(\mathrm{GNA})$ and a first order elastic analysis $M_{\mathrm{LA}}$ (LA) are plotted in Fig. 7 against $\alpha_{\mathrm{cr}}$. Eq. (9) is also plotted in the figure. The results from the frame analyses may be seen to follow the response predicted by the $k_{\text {amp }}$ expression very closely. Frames with high values of $\alpha_{\mathrm{cr}}$ are not sensitive to second order effects, and the moments from the first and second order analyses are almost equal. As $\alpha_{\text {cr }}$ reduces, second order effects become increasingly significant, with $M_{\mathrm{GNA}} / M_{\mathrm{LA}} \simeq 1.1$ at $\alpha_{\mathrm{cr}}=10$ and $M_{\mathrm{GNA}} / M_{\mathrm{LA}} \rightarrow \infty$ as $\alpha_{\mathrm{cr}}$ approaches unity.

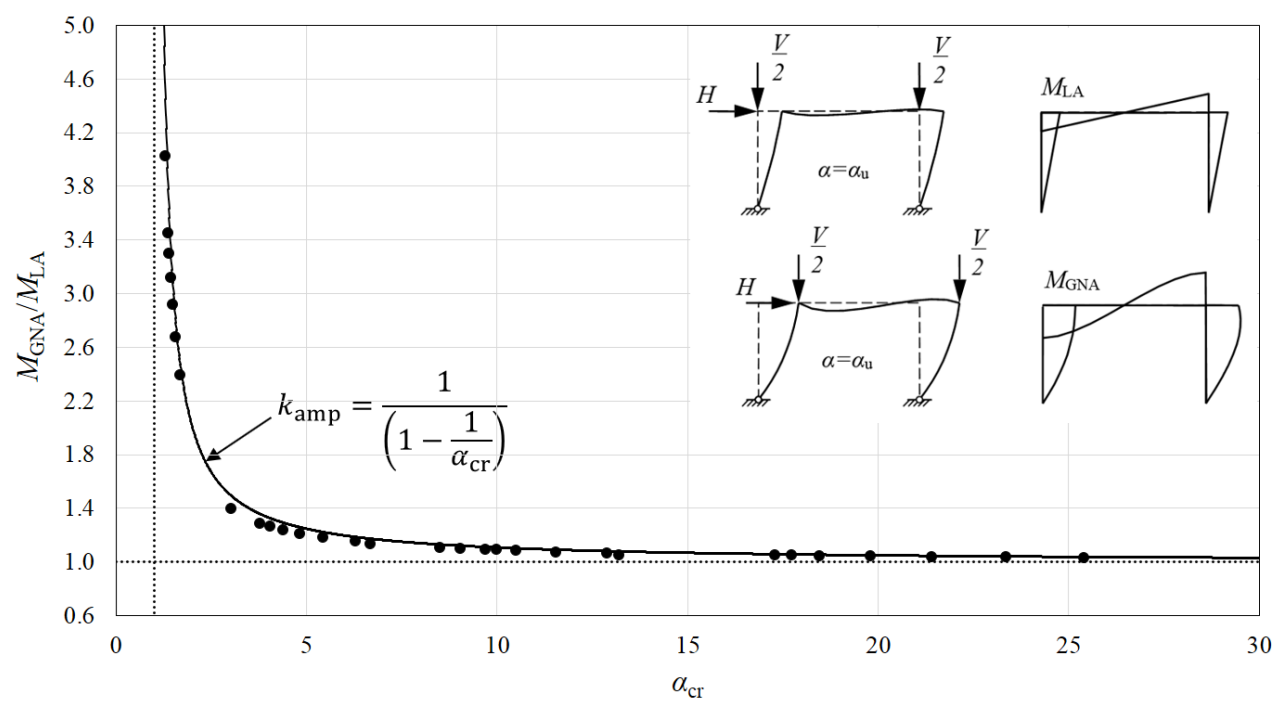

Fig. 7 Relationship between bending moments from first and second order elastic analyses at $\alpha_{\mathrm{u}}$ versus $\alpha_{\mathrm{cr}}$

To assess the impact of material nonlinearity on second order effects, first order plastic (MNA) and second order plastic (GMNA) analyses have been carried out on the same frames. The ratios of the maximum GMNA and MNA moments $M_{\mathrm{GMNA}} / M_{\mathrm{MNA}}$ extracted from the FE models at $\alpha_{\mathrm{u}}$, along with Eq. (9) are plotted against $\alpha_{\mathrm{cr}}$ in Fig. 8. Unlike in Fig. 7, the results no longer match well with the amplification factor, and there is a greater difference between the bending moments obtained from the first and second order analyses due to the influence of the nonlinear material response. Hence, by ignoring material nonlinearity, the maximum second order forces and moments in the considered frames are underestimated. 


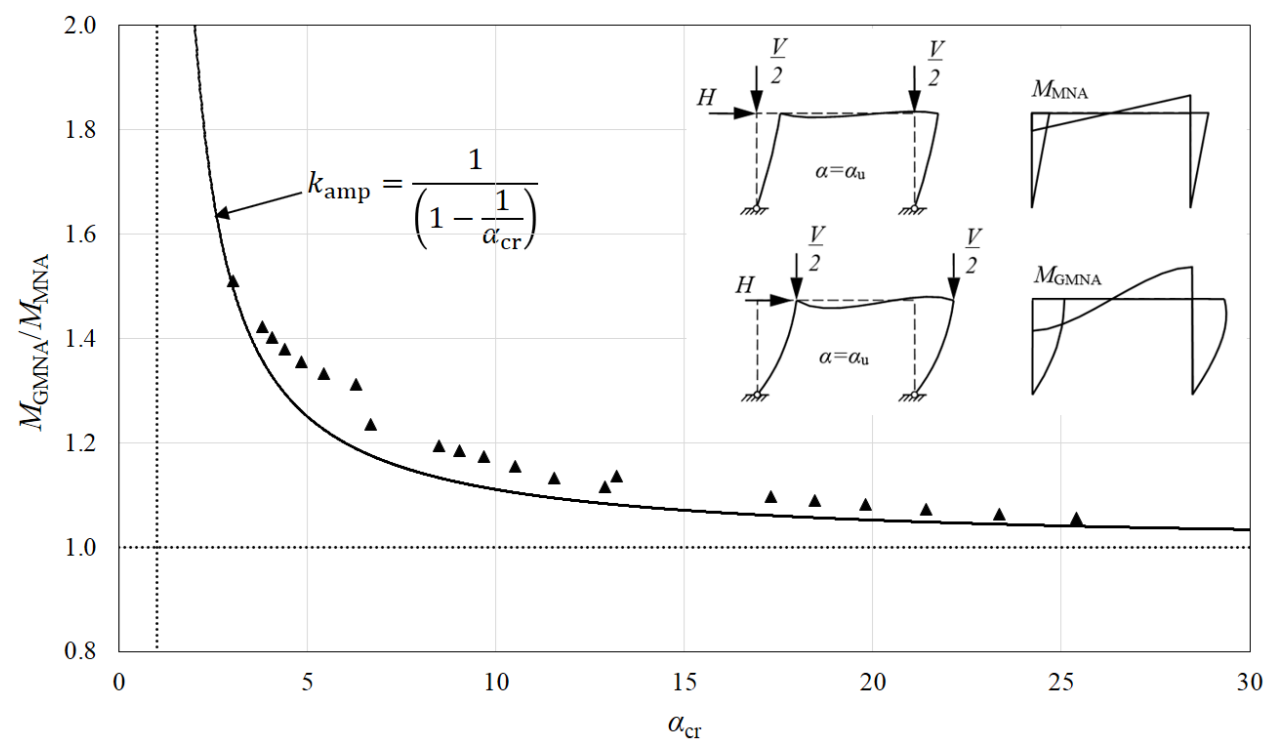

Fig. 8 Relationship between bending moments from first and second order plastic analyses at $\alpha_{\mathrm{u}}$ versus $\alpha_{\mathrm{cr}}$

\subsection{Proposal to account for the influence of plasticity on the development of second order effects}

The 'average' reduction in sway stiffness of a frame due to material nonlinearity at a specified load level can be estimated through the ratio $K_{\mathrm{s}} / K$ of the load-lateral deflection curve from a first order plastic analysis (MNA), where $K$ is the initial stiffness and $K_{\mathrm{s}}$ is the secant stiffness, as shown in Fig. 9.

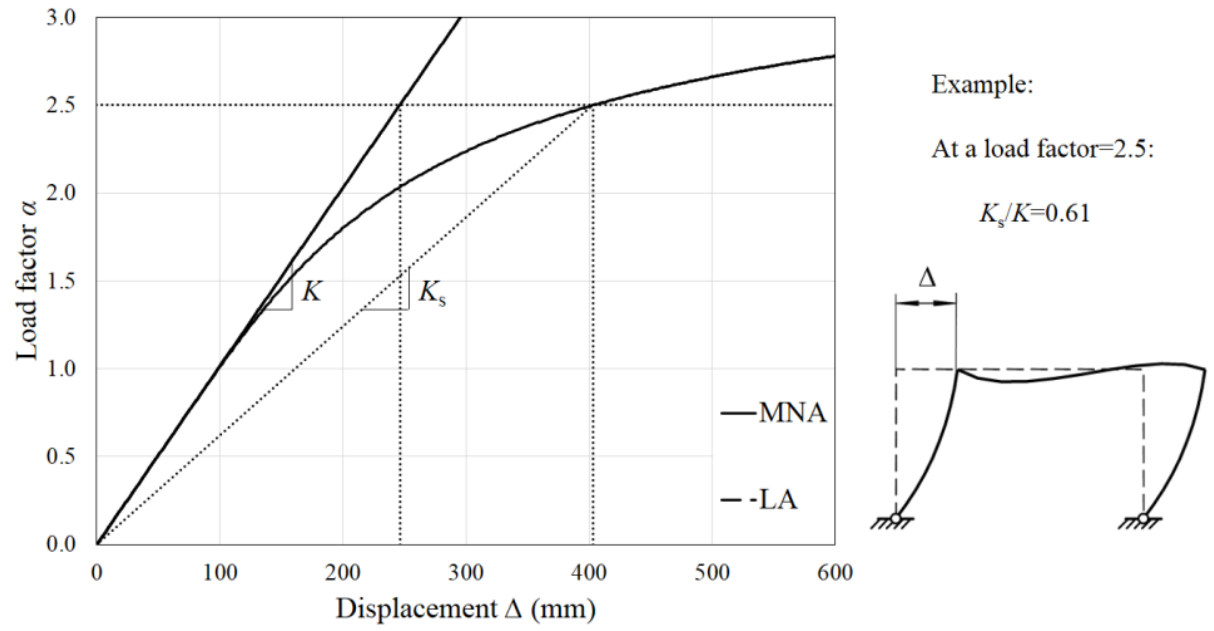

Fig. 9 Reduction to sway stiffness of frame due to material nonlinearity

As an approximation, the influence of material nonlinearity on the sway stiffness of frames may be considered by defining a modified elastic buckling load factor $\alpha_{\mathrm{cr}, \bmod }$, as given by Eq. (10). Clearly, the higher the load level, the greater the loss of stiffness due to material nonlinearity and the greater the reduction to the elastic buckling load factor of the frame, rendering it more susceptible to second order effects.

$$
\alpha_{\mathrm{cr}, \mathrm{mod}}=\alpha_{\mathrm{cr}} \frac{K_{\mathrm{s}}}{K}
$$

The ratio of GMNA to MNA moments were shown in Fig. 7 to lie on the unsafe side relative to the elastic amplifier $k_{\text {amp }}$, adopted in EN 1993-1-12], and given by Eq. (9). Based on the modified amplification factor $k_{\mathrm{amp} \text {,mod }}$ given by Eq. (11), which utilises the modified elastic buckling load factor that takes account of material nonlinearity through the secant stiffness, the frame results are replotted in Fig. 10. Good agreement between the frame results and the modified amplification factor may be observed.

$$
k_{\mathrm{amp}, \bmod }=\frac{1}{1-\frac{1}{\alpha_{\mathrm{cr}, \mathrm{mod}}}}
$$




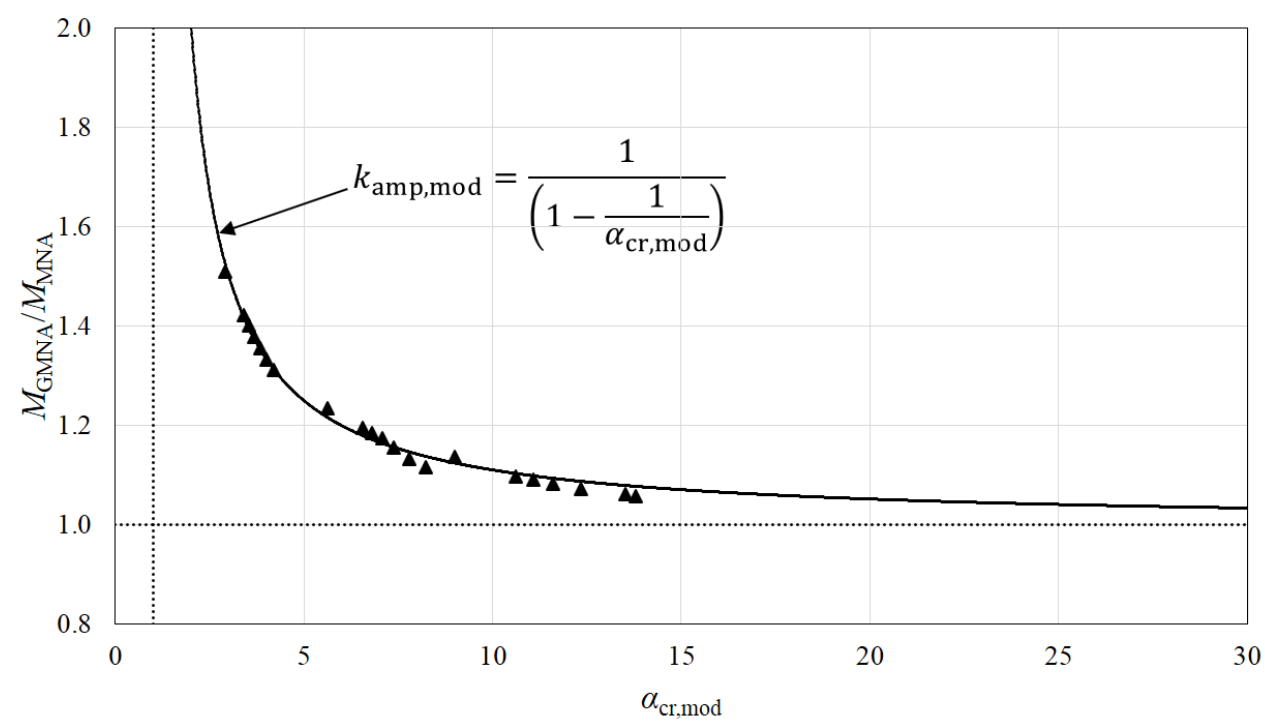

Fig. 10 Relationship between bending moments from first and second order plastic analyses at $\alpha_{\mathrm{u}}$ versus $\alpha_{\mathrm{cr}, \bmod }$

It has been shown in this section that material nonlinearity results in degradation of stiffness and hence enhanced second order effects. A method to account for the increased susceptibility to second order effects, whereby the elastic buckling load factor of the frame is reduced on the basis of the secant stiffness from a first order plastic analysis has been proposed and shown to yield accurate results. Furthermore, as an alternative to conducting a second order plastic analysis when sway effects become significant, it is suggested that a first order analysis with sway effects amplified by $k_{\text {amp,mod }}$ (Eq. (11)) could be carried out.

\section{Assessment of Design Approaches}

\subsection{Introduction}

In this section, the benchmark GMNIA results generated in Section 2 are used to assess the suitability and accuracy of a range of different design approaches, as listed in Table 2. Design approaches 1-5 employ the EN 1993-1-4 cross-section and member checks while approaches 6-10 utilise the Continuous Strength Method. The EN 1993-1-4 and CSM crosssection checks and member checks are described in Sections 3.2 and 3.3, respectively.

Following the recommendations of EN 1993-1-1, second order effects may be neglected when $\alpha_{\mathrm{cr}} \geq 10$ for elastic analysis and $\alpha_{\mathrm{cr}} \geq 15$ for plastic analysis, and a first order analysis can be used. For $\alpha_{\mathrm{cr}}<10$ (or 15), account should be taken of second order effects. The limit of 15 for plastic analysis is recognising the fact that frames have reduced stiffness following plasticity so second order effects will be greater. A more consistent approach (rather than one adjusted limit of 15 for all frames) is to determine the increased degree of flexibility on a frame by frame basis, as with the proposed $\alpha_{\text {cr,mod }}$ approach, and retain the limit of 10 for all frames and all analysis types. This will be explored further in future work, but for the comparisons presented herein, the existing limits on $\alpha_{\mathrm{cr}}$ will be employed. As an alternative to design approaches 2, 4, 7 and 9, when $\alpha_{\text {cr }}<10$ (or 15), first order analyses may be carried out with amplification to account for second order effects using Eq. (9). 
Table 2 Summary of different design approaches considered and results obtained in comparison to benchmark GMNIA results

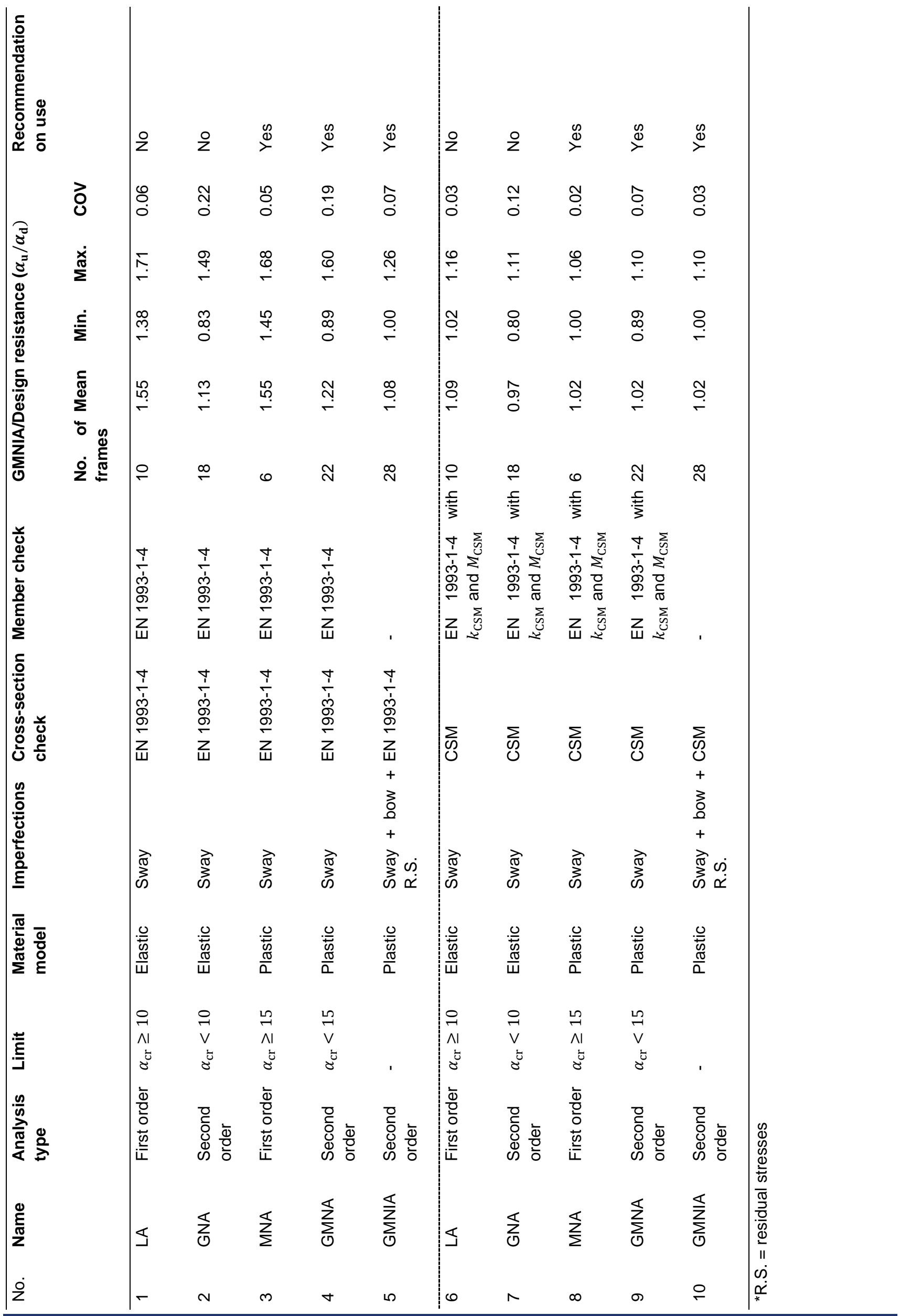

Paper presented by Fiona Walport - fiona.walport12@imperial.ac.uk

(c) Walport F, Gardner L, Nethercot D, Imperial College London \& Real E, Arrayago I, UPC 


\subsection{Cross-section checks}

The cross-section employed for the studied frames (HEB 340) is Class 1 under all considered loading conditions. The EN 1993-1-4 cross-section resistance is therefore given by $N_{\mathrm{c}, \mathrm{Rd}}=A f_{\mathrm{y}} / \gamma_{\mathrm{M} 0}$ in compression, where $A$ is the cross-sectional area and $\gamma_{\mathrm{M} 0}$ is the partial safety factor for cross-section resistance, and $M_{\mathrm{c}, \mathrm{y}, \mathrm{Rd}}=W_{\mathrm{pl}, \mathrm{y}} f_{\mathrm{y}} / \gamma_{\mathrm{M} 0}$ in bending, where $W_{\mathrm{pl}, \mathrm{y}}$ is the major axis plastic section modulus. Under combined loading, the interaction formula given in Clause 6.2.9.1 of EN 1993-1-1 is employed. The CSM cross-section compression resistance $N_{\mathrm{csm}, \mathrm{Rd}}$ for $\bar{\lambda}_{\mathrm{p}} \leq 0.68$ (as is the case for HEB 340) is given by Eq. (12), where $f_{\mathrm{csm}}$ is the limiting stress determined from the strain hardening material model, defined by Eq. (13).

$$
\begin{gathered}
N_{\mathrm{csm}, \mathrm{Rd}}=\frac{A f_{\mathrm{csm}}}{\gamma_{\mathrm{M} 0}} \quad \text { for } \quad \bar{\lambda}_{\mathrm{p}} \leq 0.68 \\
f_{\mathrm{csm}}=f_{\mathrm{y}}+E_{\mathrm{sh}} \varepsilon_{\mathrm{y}}\left(\frac{\varepsilon_{\mathrm{csm}}}{\varepsilon_{\mathrm{y}}}-1\right)
\end{gathered}
$$

The CSM cross-section bending resistance for an I-section with $\bar{\lambda}_{\mathrm{p}} \leq 0.68$, bending about the major axis $M_{\mathrm{csm}, \mathrm{y}, \mathrm{Rd}}$ is given by Eq. (14).

$$
M_{\mathrm{csm}, \mathrm{y}, \mathrm{Rd}}=\frac{W_{\mathrm{pl}, \mathrm{y}} f_{\mathrm{y}}}{\gamma_{\mathrm{M} 0}}\left[1+\frac{E_{\mathrm{sh}}}{E} \frac{W_{\mathrm{el}, \mathrm{y}}}{W_{\mathrm{pl}, \mathrm{y}}}\left(\frac{\varepsilon_{\mathrm{csm}}}{\varepsilon_{\mathrm{y}}}-1\right)-\left(1-\frac{W_{\mathrm{el}, \mathrm{y}}}{W_{\mathrm{pl}, \mathrm{y}}}\right) /\left(\frac{\varepsilon_{\mathrm{csm}}}{\varepsilon_{\mathrm{y}}}\right)^{2}\right] \text { for } \quad \bar{\lambda}_{\mathrm{p}} \leq 0.68
$$

where $W_{\mathrm{el}, \mathrm{y}}$ is the major axis elastic section modulus and $E_{\mathrm{sh}}=\left(f_{\mathrm{u}}-f_{\mathrm{y}}\right) /\left(C_{2} \varepsilon_{\mathrm{u}}-\varepsilon_{\mathrm{y}}\right)$ is the material strain hardening modulus, where $C_{2}=0.16$ for austenitic steel, and $\varepsilon_{\mathrm{csm}} / \varepsilon_{\mathrm{y}}$ is the strain ratio determined from Eq. (6).

For cross-sections with $\bar{\lambda}_{\mathrm{p}} \leq 0.60$ under combined loading, the CSM utilises the EN 1993-1-1 interaction formula, but with CSM end points, as given by Eq. (15).

$$
M_{\mathrm{R}, \mathrm{csm}, \mathrm{y}, \mathrm{Rd}}=M_{\mathrm{csm}, \mathrm{y}, \mathrm{Rd}} \frac{\left(1-\frac{N_{\mathrm{Ed}}}{N_{\mathrm{csm}, \mathrm{Rd}}}\right)}{(1-0.5 a)} \text { but } M_{\mathrm{R}, \mathrm{csm}, \mathrm{y}, \mathrm{Rd}} \leq M_{\mathrm{csm}, \mathrm{y}, \mathrm{Rd}} \text { for } \quad \bar{\lambda}_{\mathrm{p}} \leq 0.60
$$

where $a=\left(A-2 b t_{\mathrm{f}}\right) / A \leq 0.5$.

\subsection{Member checks}

Member checks are performed to verify the global stability of the members in the frame, which, in the present study, were predominately under both axial load and bending (i.e. beam-columns). These checks require the calculation of member slenderness, which in turn requires the determination of the buckling length of the members. This buckling length can conservatively be taken as the system length (provided any sway effects (for cases where $\alpha_{\mathrm{cr}}<10$ for elastic analysis or 15 for plastic analysis) are appropriately dealt with through a second order analysis or amplified first order analysis), and more accurately taken as the calculated effective length. Effective lengths take into consideration the rotational restraint provided by the end support conditions and are equal to the distance between the inflection points of the buckled shape. The effective lengths have been back calculated herein from the critical load factor using Eq. (16), where $I$ is the second moment of area, and $N_{\mathrm{Ed}}$ is the applied axial load on the column under consideration at collapse. Non-sway effective lengths have been determined in all cases, since the effects of sway are taken into account through the consideration of a second order, or amplified first order, analysis. The calculation has been performed by carrying out a linear buckling analysis under vertical loads only and with a horizontal prop at the top right of the frame to restrain lateral movement.

$$
L_{\mathrm{e}}=\sqrt{\frac{\pi^{2} E I}{N_{\mathrm{cr}}}}=\sqrt{\frac{\pi^{2} E I}{\alpha_{\mathrm{cr}} N_{\mathrm{Ed}}}}
$$

\subsubsection{EN 1993-1-4 ${ }^{[1]}$ member checks}

The EN 1993-1-4 beam-column design equations mirror those given for carbon steel in EN 1993-1-1, but with modifications to the interaction buckling factors to take into account the nonlinear material response and gradual yielding of stainless steel ${ }^{[18]}$. For members under combined compression plus major axis bending, but restrained against lateral torsional buckling, the EN 1993-1-4 beam-column member check is given by Eq. (17), where $N_{\mathrm{Ed}}$ is the design axial load, $M_{\mathrm{y}, \mathrm{Ed}}$ is the maximum applied first order bending moment about the major axis, $N_{\mathrm{b}, \mathrm{y}, \mathrm{Rd}}$ is the major axis column buckling resistance, $\gamma_{\mathrm{M} 1}$ is the partial safety factor for member buckling resistance and $k_{\mathrm{y}}$ is the interaction factor, given by Eq. (18). The interaction factor has a minimum value of 1.2 , so as to prevent overpredictions of beam-column strengths for Class 1 and 2 cross-sections ${ }^{[18]}$.

$$
\frac{N_{\mathrm{Ed}}}{N_{\mathrm{b}, \mathrm{y}, \mathrm{Rd}}}+k_{\mathrm{y}} \frac{M_{\mathrm{y}, \mathrm{Ed}}}{W_{\mathrm{pl}, \mathrm{y}} f_{\mathrm{y}} / \gamma_{\mathrm{M} 1}} \leq 1
$$




$$
k_{\mathrm{y}}=1.0+2\left(\bar{\lambda}_{\mathrm{y}}-0.5\right) \frac{N_{\mathrm{Ed}}}{N_{\mathrm{b}, \mathrm{y}, \mathrm{Rd}}} \quad \text { but } \quad 1.2 \leq k_{\mathrm{y}} \leq 1.2+2 \frac{N_{\mathrm{Ed}}}{N_{\mathrm{b}, \mathrm{y}, \mathrm{Rd}}}
$$

\subsubsection{Zhao et. al $^{[18]}$ member checks}

Zhao et al. ${ }^{[18]}$ proposed revised design equations based on a comprehensive study of the codified design methods for stainless steel square hollow section (SHS) and rectangular hollow section (RHS) beam-columns. The revised beamcolumn equation is given by Eq. (19), where $M_{\mathrm{c}, \mathrm{csm}, \mathrm{y}, \mathrm{Rk}}$ is the characteristic CSM design bending resistance, $k_{\mathrm{csm}, \mathrm{y}}$ is the updated interaction factor, given by Eq. (20) and $D_{1}, D_{2}$ and $D_{3}$ are coefficients defining the bilinear relationship between $k_{\mathrm{csm}, \mathrm{y}}$ and $\bar{\lambda}$. The coefficients used in this study are $D_{1}=2.5, D_{2}=0.35$ and $D_{3}=1.1^{[19]}$.

$$
\begin{gathered}
\frac{N_{\mathrm{Ed}}}{N_{\mathrm{b}, \mathrm{y}, \mathrm{Rd}}}+k_{\mathrm{csm}, \mathrm{y}} \frac{M_{\mathrm{y}, \mathrm{Ed}}}{M_{\mathrm{c}, \mathrm{csm}, \mathrm{y}, \mathrm{Rk}} / \gamma_{\mathrm{M} 1}} \leq 1 \\
k_{\mathrm{csm}, \mathrm{y}}=1+D_{1}\left(\bar{\lambda}-D_{2}\right) \frac{N_{\mathrm{Ed}}}{N_{\mathrm{b}, \mathrm{y}, \mathrm{Rd}}} \quad \text { but } \quad k_{\mathrm{csm}, \mathrm{y}} \leq 1+D_{1}\left(D_{3}-D_{2}\right) \frac{N_{\mathrm{Ed}}}{N_{\mathrm{b}, \mathrm{y}, \mathrm{Rd}}}
\end{gathered}
$$

\subsection{Results}

The mean, minimum and maximum ratio of GMNIA to design resistances $\left(\alpha_{\mathrm{u}} / \alpha_{\mathrm{d}}\right)$ for the 10 considered design approaches (5 Eurocode and 5 CSM based) are shown in Table 2, along with the corresponding coefficients of variation (COV) of the ratios for the 28 studied frames. Results below unity indicate design predictions on the unsafe side.

The mean benchmark to predicted failure load ratios $\alpha_{\mathrm{u}} / \alpha_{\mathrm{d}}$ for design approaches 1-5 (Eurocode based) are 1.55, 1.13, 1.55, 1.22 and 1.08, respectively, and the corresponding COVs are 0.06, 0.22, 0.05, 0.19 and 0.07. The mean benchmark to predicted failure load ratios $\alpha_{\mathrm{u}} / \alpha_{\mathrm{d}}$ for design approaches 6-10 (CSM based) are 1.09, 0.97, 1.02, 1.02 and 1.02, respectively, and the corresponding COVs are 0.03, 0.12, 0.02, 0.07 and 0.03. The CSM mean values are closer to unity than those resulting from the European code and thus indicate improved accuracy, as also illustrated in Fig. 11. The COVs show that the CSM based design approaches generally result in scatter around half that of the EN 1993-1-4 design approaches.

It was shown in Section 2.4 that neglecting material nonlinearity results in underpredicted second order moments and it is therefore recommended that a plastic global analysis should always be considered. The CSM design approach considers the beneficial effects of strain hardening and this is reflected in the significantly more accurate results of the CSM design approaches (6-10) compared with the EN 1993-1-4 design approaches (1-5) in Table 2. The Eurocodes currently state that it is sufficient to assume an elastic global analysis, corresponding to design approaches 1 and 2 . These give $\alpha_{\mathrm{u}} / \alpha_{\mathrm{d}}$ ratios ranging between of 1.38 and 1.71 and 0.83 and 1.49 , respectively i.e. the design predictions are highly scattered and range from being unconservative in some cases to excessively conservative in others. Considering design approaches 8 and 9 , the design predictions are vastly improved with $\alpha_{\mathrm{u}} / \alpha_{\mathrm{d}}$ ratios ranging between 1.00 and 1.06 and 0.89 and 1.10 , respectively. Therefore, the most accurate and consistent design predictions are achieved by employing a plastic global analysis with CSM beam-column member checks.

The EN 1993-1-4 design approaches 3 (for $\alpha_{\mathrm{cr}} \geq 15$ ) and 4 (for $\alpha_{\mathrm{cr}}<15$ ) and the CSM design approaches 8 (for $\alpha_{\text {cr }} \geq 15$ ) and 9 (for $\alpha_{\text {cr }}<15$ ) are compared against the benchmark GMNIA results in Fig. 11, where the accuracy of the design predictions are presented as a function of $\alpha_{\mathrm{cr}}$. For high $\alpha_{\mathrm{cr}}$ values, design approach 3 (EN 1993-1-4 based) results in overconservative strength predictions, with a mean value of 1.55 , while design approach 8 (CSM based) results in much more accurate strength predictions, with a mean value of 1.02. For very low $\alpha_{\text {cr }}$ values $\left(\alpha_{\text {cr }}<2\right)$ both design approaches lead to results on the unsafe side with a common minimum value of $\alpha_{\mathrm{u}} / \alpha_{\mathrm{d}}$ of 0.89 , though such flexible frames are very unlikely to be encountered in practice.

Finally, comparing design approaches 5 and 10, it can be observed that both lead to accurate results, with mean $\alpha_{\mathrm{u}} / \alpha_{\mathrm{d}}$ ratios of 1.08 and 1.02, respectively, though the Eurocode cross-section results in rather conservative design prediction in some cases, with the maximum $\alpha_{\mathrm{u}} / \alpha_{\mathrm{d}}$ ratio being 1.26. This is reduced to a maximum value of 1.10 when the CSM crosssection checks are employed. 


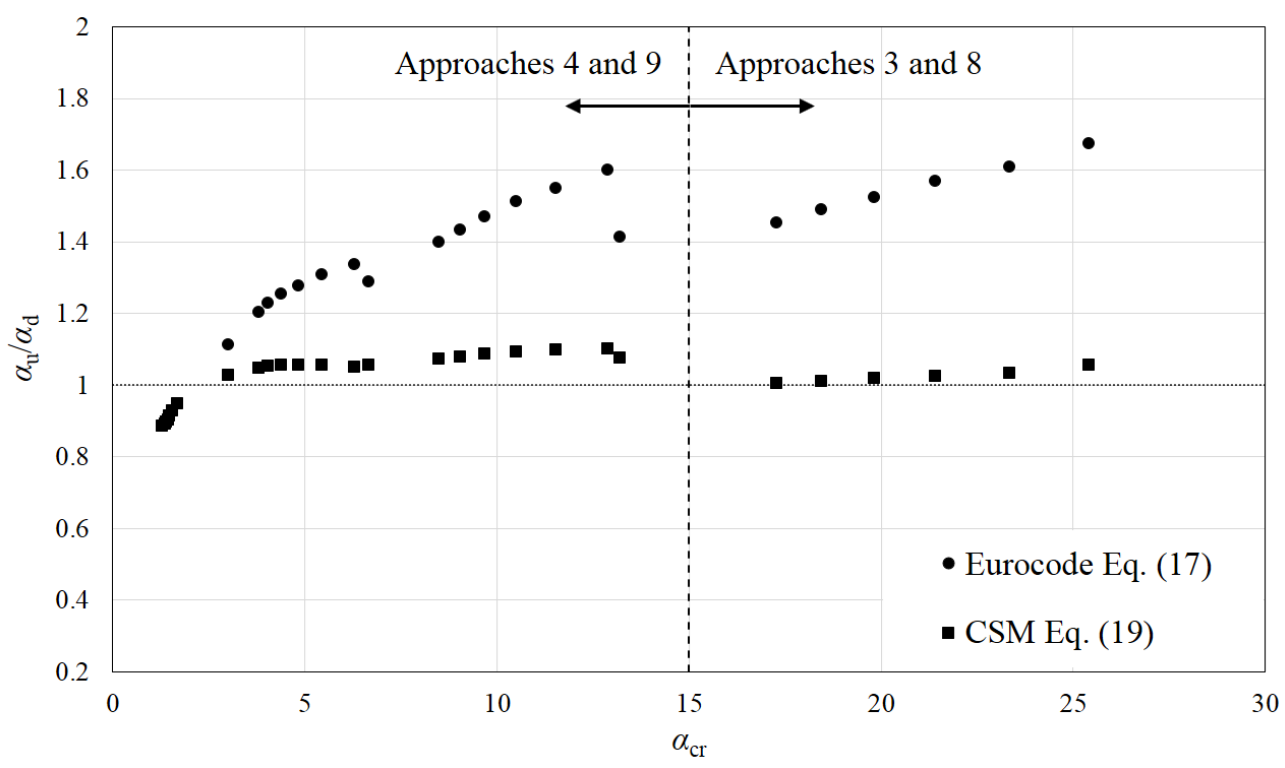

Fig. 11 Comparison of the EN 1993-1-4 and CSM design approaches for plastic analyses

\section{Discussion and Design Recommendations}

In this section, the key results from the study are discussed and suitable design recommendations for the global analysis and design of stainless steel frames are made. In Section 2, it was shown that neglecting material nonlinearity resulted in underpredicted second order moments for the 28 frames considered. A modified critical buckling load factor was therefore proposed on the basis of the secant stiffness from a first order plastic analysis, and shown to provide an accurate measure of the susceptibility of the frame to second order effects. The benchmark GMNIA results generated in Section 2 were used to assess the current design approaches in Section 3, with the Continuous Strength Method design provisions resulting in improved accuracy and reduced scatter over the EN 1993-1-4 design provisions.

Based on the results, summarised in Table 2, the following observations and recommendations are made:

- A plastic global analysis should always be employed to prevent the underprediction of second order moments in stainless steel frames

- The Continuous Strength Method (CSM) design provisions result in significantly more accurate strength predictions compared with EN 1993-1-4 due to the consideration of strain hardening

- For the plastic global analysis of stainless steel frames either (i) a first order analysis should be carried out when $\alpha_{\mathrm{cr}} \geq 15$ and a second order analysis performed when $\alpha_{\mathrm{cr}}<15$ or, (ii) a first order analysis carried out when $\alpha_{\mathrm{cr}, \mathrm{mod}} \geq 10$ and a second order analysis performed when $\alpha_{\mathrm{cr} \text {,mod }}<10$. As an alternative to a second order plastic analysis, a first order analysis with amplification $k_{\text {amp,mod }}$ (yielding similar results to second order analysis) may be performed.

- Advanced analysis (GMNIA) with cross-section checks (i.e. design approaches 5 and 10) yields very accurate results, particularly when the CSM cross-section checks are employed.

\section{Conclusions}

The importance of making adequate allowances for the influence of second order effects when conducting global analysis and design of frames employing stainless steel members has been examined by comparing the findings from a series of numerical analyses that employ different combinations of analysis method and cross-section/member design checks. The benchmark against which all design approaches have been assessed is GMNIA, with the Continuous Strength Method (CSM) employed to simulate local buckling. Current stainless steel design methods are based on the behaviour of frames made from carbon steel, for which the early material softening is absent, meaning that second order effects for stainless steel are likely to be more significant and limits of application for existing/approximate methods questionable.

The degradation of stiffness significantly affects the characteristics of the structural system and subsequent distribution of internal forces and moments. If material nonlinearity is considered in the global analysis of a frame, greater deflections ensue due to the loss of material stiffness. Therefore, without the consideration of plasticity, moments are underpredicted, as shown in Section 2.4. It is recommended that material nonlinearity should always be considered in the global analysis of stainless steel frames to account for the increased susceptibility to second order effects. For all frames, when $\alpha_{\mathrm{cr}} \geq 15$, second order effects may be neglected and a first order plastic analysis (MNA) carried out. For $\alpha_{\mathrm{cr}}<15$ a second order plastic analysis (GMNA) should be carried out. A new design procedure based on the calculation of a modified critical buckling load with reduced stiffness, representing the behaviour of the frame after a certain degree of plastification, has 
been outlined. For all frames, when $\alpha_{\mathrm{cr}, \text { mod }} \geq 10$, second order effects may be neglected and a first order plastic analysis (MNA) carried out. For $\alpha_{\mathrm{cr} \text { mod }}<10$ a second order plastic analysis (GMNA) should be carried out or, alternatively, a first order plastic analysis with amplification $k_{\text {amp,mod }}$ (yielding similar results to a second order plastic analysis) may be performed.

Current design provisions have been assessed against the benchmark GMNIA results. It was found that EN 1993-1-4 generally provides conservative results due to the neglect of strain hardening in the cross-section and beam-column member checks. The CSM design provisions were also assessed and shown to give significantly more accurate predictions, with reduced scatter, due to account being made for strain hardening. Overall, the most accurate and consistent predictions were achieved by employing a plastic global analysis with CSM cross-section and beam-column member checks. In this case, mean benchmark to predicted failure load ratios $\alpha_{\mathrm{u}} / \alpha_{\mathrm{d}}$ of 1.02 and 1.02 for first order (MNA) and second order (GMNA) analyses (i.e. design approaches 8 and 9), respectively. This is a significant improvement over the current approach (i.e. design approaches 1 and 2) which results in mean ratios of 1.55 and 1.13 for first order (LA) and second order (GNA) analyses, respectively.

\section{References}

[1] EN 1993-1-4. Eurocode 3 - Design of steel structures - Part 1-4: General rules - Supplementary rules for stainless steel. Brussels: European Committee for Standardisation (CEN); 2006.

[2] EN 1993-1-1. Eurocode 3 - Design of steel structures - Part 1-1: General rules and rules for buildings. Brussels: European Committee for Standardisation (CEN); 2005

[3] Theofanous, M., Saliba, N., Zhao, O. and Gardner, L. Ultimate response of stainless steel continuous beams. ThinWalled Structures, 83, 115-127; 2014.

[4] Mirambell, E. and Real, E. On the calculation of deflections in structural stainless steel beams: an experimental and numerical investigation. Journal of Constructional Steel Research, 54(1), 109-133; 2000.

[5] Rasmussen, K.J.R. Full-range stress-strain curves for stainless steel alloys. Journal of Constructional Steel Research, 59(1), 47-61;2003.

[6] Arrayago, I., Real, E., and Gardner, L. Description of stress-strain curves for stainless steel alloys. Materials and Design, 87, 540-552; 2015.

[7] Abaqus. Abaqus CAE User's Manual, Version 6.14. Pawtucket: Hibbitt, Karlsson and Sorenson, Inc; 2014.

[8] Horne, M.R. Elastic-plastic failure loads of plane frames. Royal Society - Proceedings Series A, 274(1358), 343$364 ; 1963$

[9] Kucukler, M., Gardner, L. and Macorini, L. Development and assessment of a practical stiffness reduction method for the in-plane design of steel frames. Journal of Constructional Steel Research, 126, 187-200; 2016.

[10] Gardner, L. and Ng, K.T. Temperature development in structural stainless steel sections exposed to fire. Fire Safety Journal, 41(3), 185-203; 2006.

[11] ECCS. Ultimate limit state calculations of sway frames with rigid joints. European Convention for Constructional Steelwork; 1984

[12] Yuan, H.X., Wang, Y.Q., Shi, Y.J., and Gardner, L. Residual stress distributions in welded stainless steel sections. Thin-Walled Structures, 106, 330-345; 2016.

[13] Gardner, L. The continuous strength method. Proceedings of the Institution of Civil Engineers - Structures and Buildings, 161(3), 127-133; 2008.

[14] Afshan, S. and Gardner, L. The continuous strength method for structural stainless steel design. Thin-Walled Structures, 68, 42-49; 2013.

[15] Li, Z. and Schafer, B.W. Buckling analysis of cold-formed steel members with general boundary conditions using CUFSM: conventional and constrained finite strip methods. Proceedings of the $20^{\text {th }}$ International Speciality Conference on Cold-Formed Steel Structures, 17-31; 2010.

[16] Lay, M.G. Some studies of flange local buckling in wide-flange shapes. Proc. ASCE, Vol. 91, ST6, Publication No. 288 (65-23). Fritz Laboratory Reports. Paper 195; 1965 
[17] Merchant, W. The failure load of rigid jointed frameworks as influenced by stability. The Structural Engineer; 1954

[18] Zhao, O., Gardner, L., and Young, B. Behaviour and design of stainless steel SHS and RHS beam-columns. ThinWalled Structures, 106, 330-345; 2016.

[19] Bu. Y., Gardner, L. Experimental and numerical studies of laser-welded stainless steel I-section beam-columns. Proceedings of the Fifth International Experts Seminar, London, UK; 2017. 